\title{
Polychlorinated Dibenzo-p-dioxins (PCDDs) and Dibenzofurans (PCDFs) and Polychlorinated Biphenyls (PCBs) in Water Samples from the Middle Reaches of the Yangtze River, China
}

\author{
Qin Zhang • Lirong Gao • Minghui Zheng • \\ Lidan Liu $\cdot$ Cheng Li
}

Received: 17 September 2013/ Accepted: 24 December 2013/Published online: 4 January 2014

(C) Springer Science+Business Media New York 2014

\begin{abstract}
Few studies have been conducted to investigate the polychlorinated dibenzo- $p$-dioxins (PCDDs), dibenzofurans (PCDFs) and polychlorinated biphenyls (PCBs) in freshwater since the volume of water needed for dioxin analysis is large. In this study, 19 water samples from the middle reaches of the Yangtze River were analysed for the levels of PCDD/Fs and dioxin-like PCBs (dl-PCBs). The results showed that the concentration ranges of $\mathrm{PCDD} / \mathrm{Fs}$ and dl-PCBs were $0.6-8.5$ and $2.0-15.8 \mathrm{pg} / \mathrm{L}$, respectively, which were relatively low compared with those reported in the literature. The WHO-TEQ concentration range of dioxins was $0.002-0.040 \mathrm{pg} / \mathrm{L}$. The PCA results indicated that the main sources of PCDD/Fs may be the applications of pentachlorophenol or sodium pentachlorophenate and domestic wood and coal burning. For dl-PCBs, domestic wood burning and coal burning were the main sources.
\end{abstract}

Keywords PCDD/Fs - PCBs - Yangtze River - Water

Polychlorinated dibenzo- $p$-dioxins and dibenzofurans (PCDD/Fs) and polychlorinated biphenyls (PCBs) are chemically stable and hydrophobic organic chemicals that persist in the environment and are thought to be biomagnified via the food chain (Binelli and Provini 2003). Due to their inherent chemical and physical properties, bioaccumulation of these compounds in aquatic biota is of increasing concern. Sediment samples have been frequently studied because they

Q. Zhang $\cdot$ L. Gao $(\bowtie) \cdot$ M. Zheng $\cdot$ L. Liu $\cdot$ C. Li

State Key Laboratory of Environmental Chemistry and Ecotoxicology, Research Center for Eco-Environmental Sciences, Chinese Academy of Sciences,

P.O. Box 2871, Beijing 100085, People's Republic of China

e-mail: gaolr@rcees.ac.cn can reveal historical trends of dioxin accumulation (Chi et al. 2007). The study of PCDD/Fs in water bodies is of great interest because the food chain is the main pathway of human exposure to dioxins. However, few studies have been conducted on water because the volume of water needed for dioxin analysis is large.

The Yangtze River is $6,397 \mathrm{~km}$ long and has a mean annual water discharge of $29,400 \mathrm{~m}^{3} / \mathrm{s}$ (Zhang 1995). It is the longest river in Asia and the third largest river in the world and it remains to be the most important water source in China. It originates in Qinghai Province and flows through 11 provinces and municipalities, and finally flows into the East China Sea. Industrial waste discharges, runoff from land containing agricultural fertilizers, pesticides and herbicides, as well as heavy metal pollution have resulted in the Yangtze being one of the most polluted rivers in the world. While there have been studies on dissolved inorganic phosphate, dissolved inorganic nitrogen and trace element $(\mathrm{Pb}, \mathrm{Cd}, \mathrm{Cr}, \mathrm{Ni}, \mathrm{Cu}$ et al.) levels in the Yangtze river (Müller et al. 2008), to the authors' knowledge, there have been few studies on the levels of persistent organic pollutants. The aim of this study was to carry out a survey of PCDD/Fs and dl-PCBs in the Yangtze River water. The levels, distributions and congener profiles of PCDD/Fs and PCBs were investigated in this study. For providing helpful information for reducing the levels of these compounds in this area, the possible sources of PCDD/Fs and PCBs were identified using principal component analysis (PCA).

\section{Materials and Methods}

Water samples were collected at 19 sampling sites located in the middle reaches of the Yangtze River in June 2010 (Fig. 1). At each sampling site, about $20 \mathrm{~L}$ water was 
Fig. 1 WHO-TEQ

concentrations $(\mathrm{pg} / \mathrm{L})$ of dioxins in the Yangtze River

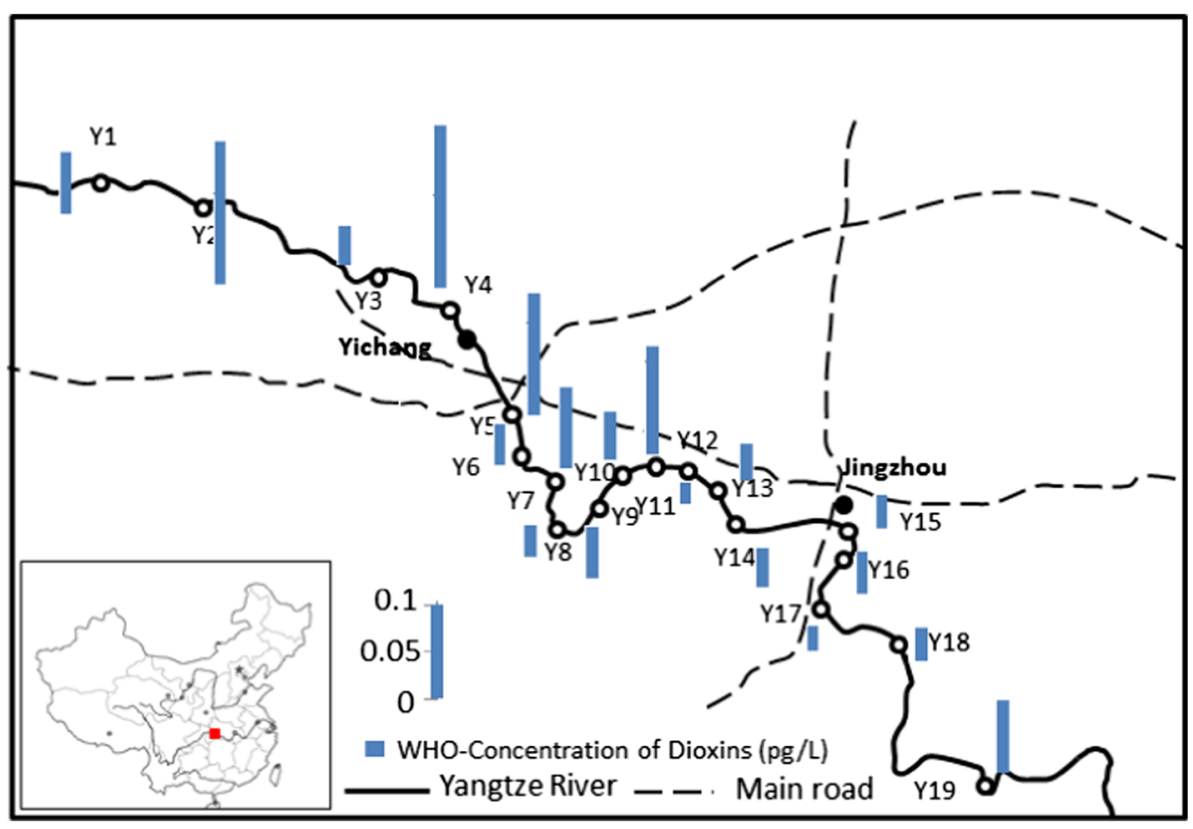

collected with a stainless-steel submersible pump and was pumped into $10 \mathrm{~L}$ pre-cleaned brown glass containers. The glass containers were returned to the laboratory within a few hours and placed in a refrigerator until the beginning of the pretreatment. During pretreatment, the water was suction filtered through a glass-fiber filter (GF/C, $47 \mathrm{~mm}$, glass microfiber filters, Whatman, England). After that, the water sample was extracted using a solid phase $(47 \mathrm{~mm}$, Empore C18 SPE, 3 M, USA) extraction apparatus. The solid phase from the filtration process was air-dried. PCDD/Fs and PCBs were prepared and analyzed following the method described in our previous study (Hui et al. 2009). The solid phase and the glass-fiber were then extracted by Accelerated Solvent Extraction (ASE350, Dionex, USA). The extracts were cleaned up with a silica gel column (treated with $44 \%$ sulfuric acid), a multi-layer silica column and a basic alumina column. PCDD/Fs and PCBs were analyzed by high resolution gas chromatography (Agilent 6890, Agilent Tech., USA) coupled with high resolution mass spectrometry (HRGC/HRMS) (Micromass Autospec Ultima, Waters, UK).

Field and laboratory blanks were taken with each set of samples and processed in an identical manner to the samples. The recoveries for the surrogate standards of PCDD/ Fs ranged from $76 \%$ to $120 \%$, which met the recovery limit demand of US EPA Method 1613. Similarly, the recoveries of $\mathrm{PCBs}$ ranged from $70 \%$ to $128 \%$, which also met the requirements of US EPA Method 1668. The limit of detection (LOD) in this study was defined at three times the signal/noise $(\mathrm{S} / \mathrm{N})$ ratio. The LOD ranged from 0.006 to $0.1 \mathrm{pg} / \mathrm{L}$ for PCDD/Fs, and from 0.007 to $1.6 \mathrm{pg} / \mathrm{L}$ for dl-PCBs. When concentrations were below the LOD, a value of half the LOD was used to calculate the total concentrations.

PCA was performed using SPSS 18.0 (Windows software package). When concentrations were below the LOD, a value of half the LOD was used. Principal components with eigenvalues greater than 1 were considered.

\section{Results and Discussion}

The concentrations of $\sum \mathrm{PCDD} / \mathrm{Fs}$ in the Yangtze River ranged from 0.6 to $6.8 \mathrm{pg} / \mathrm{L}$ (Table 1) which were comparable with those reported for ground water in Japan (Kim et al. 2002). The $\sum$ PCDD/Fs concentrations in samples collected from industrialized areas such as the River Kanzaki (Kishida 2013) were more than ten times higher than those from this study. That indicated the levels of PCDD/Fs in the Yangtze River were very low.

The concentrations of $\sum$ PCBs ranged from 2.0 to $15.7 \mathrm{pg} / \mathrm{L}$, and had a mean value of $6.1 \mathrm{pg} / \mathrm{L}$ (Table 1). The concentration ranges of total PCBs in drinking water from Japan (Kim et al. 2002) were comparable to those in this study. Kumar et al. (2012) reported that total dl-PCB concentrations were higher in surface water from various sources in India than those found in this study. Compared with other studies, the concentrations of PCBs in the Yangtze River were very low.

Toxic equivalency quotients (TEQs) were calculated for each sample (Van den Berg et al. 2006). The total WHOTEQ concentrations at all sites ranged from 0.028 to $0.177 \mathrm{pg} / \mathrm{L}$ (Fig. 1). Total WHO-TEQ concentrations of dioxins were higher at sites Y2, Y4 and Y5 than at the 


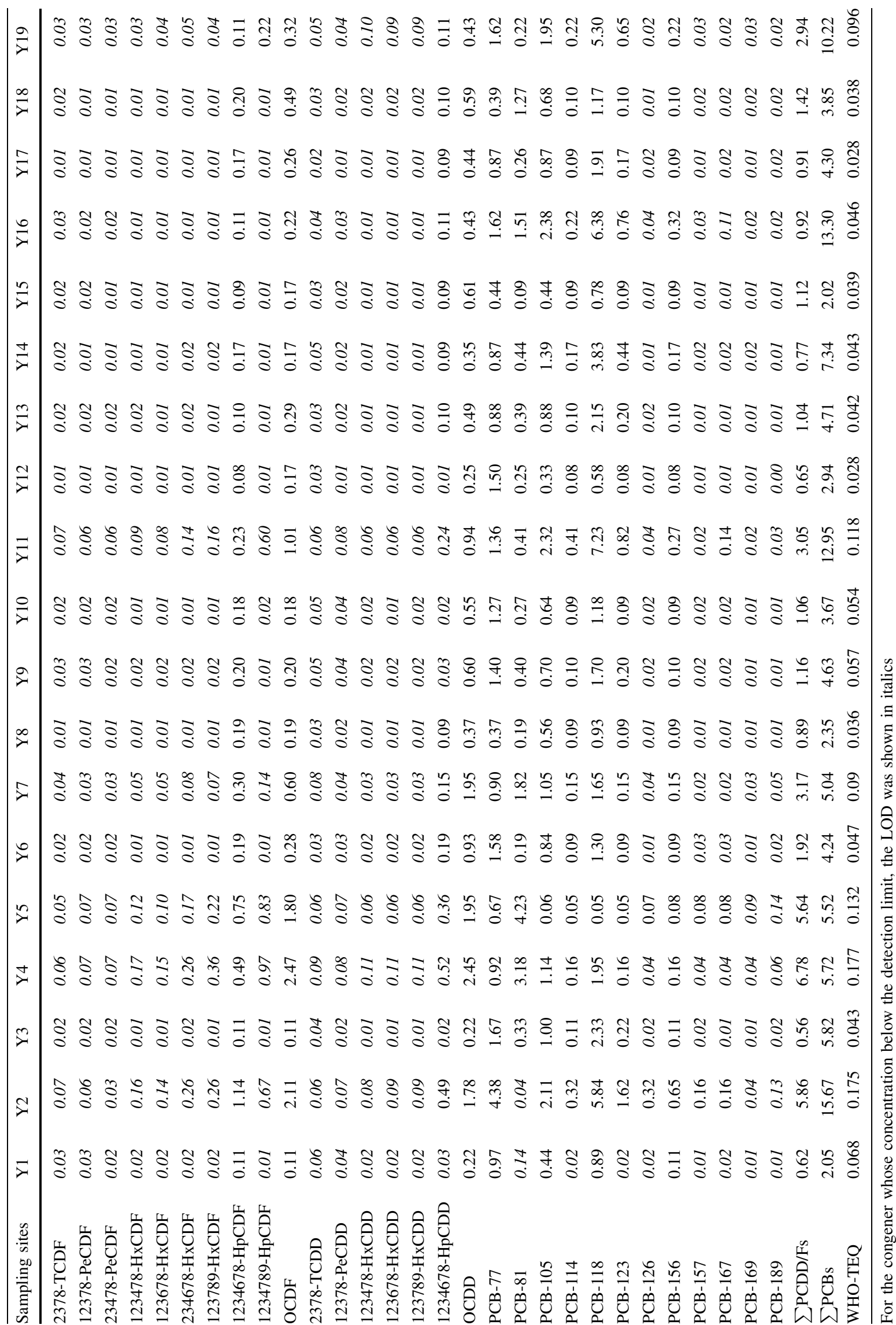


other sites. The highest WHO-TEQ concentration of total dioxins was in water sample $\mathrm{Y} 4$ collected from Yichang, in which the concentration was 6 times higher than that in sample Y12, collected from Zhijiang. Sample Y2 collected near Yichang also had a high WHO-TEQ concentration. Sample Y5 was collected from the confluence of the Yangtze River with the Xiangxi River (a highly polluted river), which may be the reason why the concentrations were comparably high.

The congener profiles for 2,3,7,8-PCDD/Fs were similar at most sampling sites with the exception of Y19. The dominant congener was OCDD, OCDF and 1,2,3,4,6,7,8HpCDF. These congeners comprised $34.4 \%-95.8 \%$ of the total PCDD/Fs concentration. This result is comparable to those reported for other studies. To further confirm the pollution sources, PCA was conducted for the 19 water samples and suspected PCDD/Fs sources. The congener profiles that hepta- and octa-chlorinated dibenzo- $p$-dioxins and chlorinated dibenzofurans are abundant at every site correspond well with byproducts of PCP and Na-PCP (Bao et al. 1995). Zheng et al. (2001) reported that waste water from pulp mills was a source of PCDD/Fs. There are numerous pulp mills in the middle and lower reaches of the Yangtze River. Up until 2012, there were no municipal solid waste or large-scale medical waste incineration plants in the sampling region. Other combustion processes such as domestic wood and coal burning may contribute to the PCDD/Fs in the Yangtze River (Lee et al. 2005). PCA was conducted for the seventeen 2,3,7,8-substituted congeners in 19 water samples and suspected PCDD/Fs sources (Fig. 2). The PCA results showed that PC1 accounted for $83.6 \%$, and PC2 accounted for $6.8 \%$, of total variability, together accounting for $90.4 \%$ of the total variability among the samples. Therefore, most of the PCDD/Fs variation in the data set can be explained by the first two components. In the score plot, samples Y1 - Y18 appeared to cluster together with PCP, Na-PCP and domestic wood and coal burning, but were separated from the data point for waste water from pulp mills. This suggests that PCP or Na-PCP use and domestic wood and coal burning are the main PCDD/Fs sources for these 18 water samples. The Y19 data point was separated from other points because of the high level of $1,2,3,4,7,8,9-\mathrm{HpCDF}$. Also, the dominant congeners in the waste water from pulp mills differed from those in the other samples. This explained why the waste water sample from pulp mills was far away from the other water samples in the PCA score plot, and suggested that waste water from pulp mills was not the main source of $\mathrm{PCDD} / \mathrm{Fs}$ in the Yangtze River.

PCB118 was the major contributor to 12 dl-PCBs. The other dominant congeners were PCB77, PCB81 and PCB105. These four congeners made up $89.4 \%$ of the

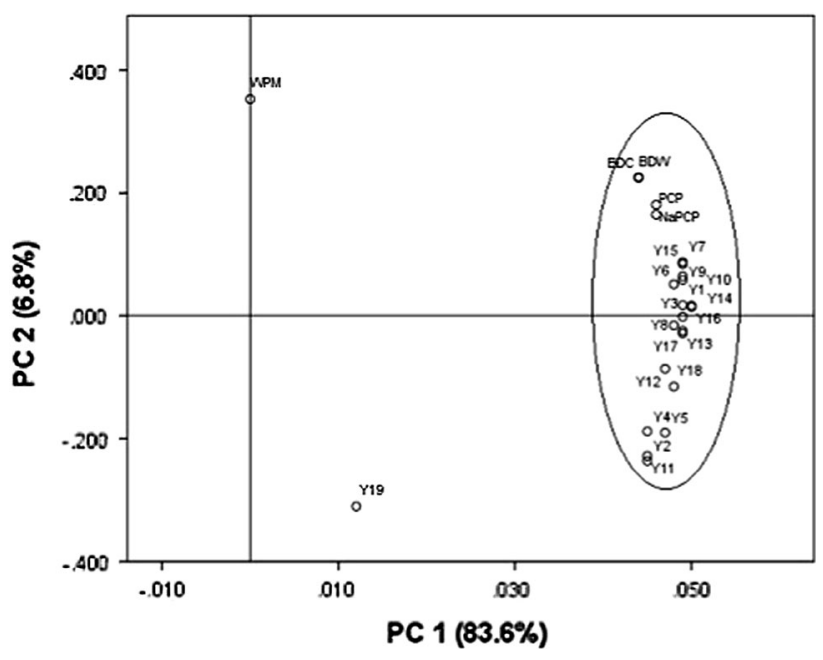

Fig. 2 PCA score plot of the PCDD/Fs in water samples from the Yangtze River and suspected PCDD/Fs source $(B D C$ buring of domestic coal, $B D W$ buring of domestic wood, $W P M$ waste water from pulp mills, $P C P$ byproducts of $\mathrm{PCP}, \mathrm{NaPCP}$ byproducts of $\mathrm{Na}-$ PCP)

total PCBs. PCA was used to identify the sources of PCBs in water samples in the Yangtze River for the 19 water samples and suspected PCBs sources. Of the 12 congeners, concentrations of some of the lower chlorinated congeners were much higher than those of the highly chlorinated congeners. This suggested that dl-PCBs in the Yangtze River water may be derived from the use or production of Chinese technical products PCB3 and PCB5 (Jiang et al. 1997). The dominant congeners in dl-PCBs from domestic coal and wood burning were similar with this study (Lee et al. 2005), so domestic coal burning and wood burning were possible sources of PCBs in the Yangtze River. PCA was conducted for the twelve dioxin-like congeners in 19 water samples and suspected PCBs sources (Fig. 3). The PCA results showed that PC1 accounted for $76.2 \%$, and PC2 accounted for $10.5 \%$, of total variability. Together, these two PCs accounted for $86.7 \%$ of total variability among the samples. Therefore, most of the PCBs variation in the dataset can be explained by the first two components. At least three clusters can be identified in the score plots. Most samples were grouped in cluster 1 and were separated from Y12 and Y15. Y12 and Y15 were grouped with PCB3 in cluster 2, and with PCB5 in cluster three. For most samples, contamination of PCBs did not correlate with the use and production of PCB3 and PCB5, which were the main source of PCBs in samples Y12 and Y5. On the contrary, based on their proximity in the PCA score plot, domestic coal burning and wood burning were the main sources of PCBs. 


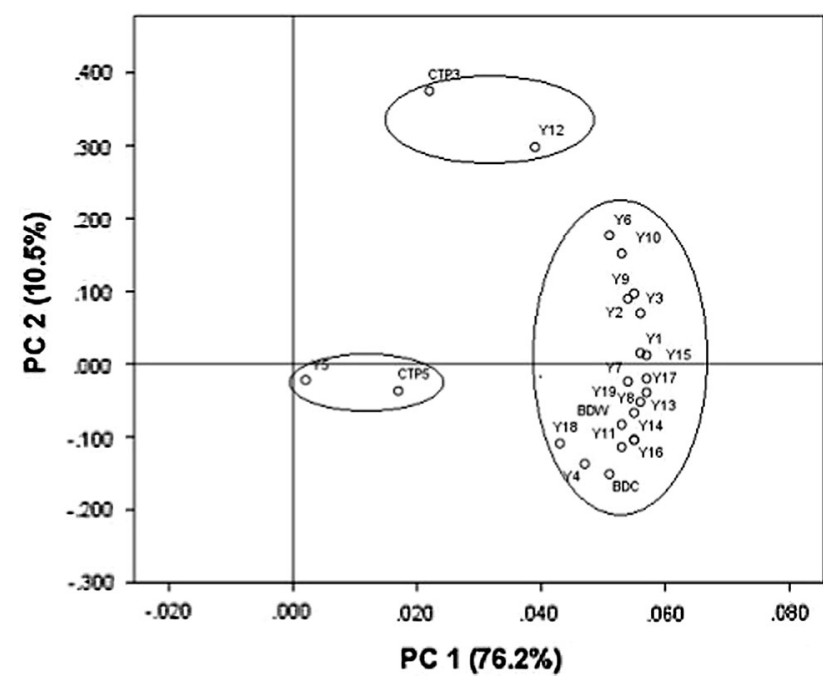

Fig. 3 PCA score plot of the dl-PCBs in water samples from the Yangtze River and suspected dl-PCBs sources ( $B D C$ buring of domestic coal, $B D W$ buring of domestic wood, CTP3 chinese technical products PCB3, CTP5 chinese technical products PCB5)

Acknowledgments This study was financially supported by the Chinese Academy of Sciences (Grant KZXZ-YW-JS406), National Natural Science Foundation of China (21007084, 21321004).

\section{References}

Bao Z, Wang K, Kang J, Zhao L (1995) Analysis of polychlorinated dibenzo-p-dioxins and polychlorinated dibenzofurans in pentachlorophenol and sodium pentachlorophenate. China Environ Chem 14:317-321
Binelli A, Provini A (2003) The PCB pollution of Lake Iseo (N. Italy) and the role of biomagnification in the pelagic food web. Chemosphere 53:143-151

Chi KH, Chang MB, Kao SJ (2007) Historical trends of PCDD/Fs and dioxin-like PCBs in sediments buried in a reservoir in Northern Taiwan. Chemosphere 68:1733-1740

Hui Y, Zheng M, Liu Z, Gao L (2009) PCDD/Fs and dioxin-like PCBs in sediments from Yellow Estuary and Yangtze Estuary China. Bull Environ Contam Toxicol 83:614-619

Jiang K, Li L, Chen Y, Jin J (1997) Determination of PCDD/Fs and dioxin-like PCBs in Chinese commercial PCBs and emissions from a testing PCB incinerator. Chemosphere 34:941-950

Kim HK, Masaki H, Matsumura T, Kamei T, Magara Y (2002) Removal efficiency and homologue patterns of dioxins in drinking water treatment. Water Res 36:4861-4869

Kishida M (2013) Distribution characteristics and source identification of polychlorinated dibenzo-p-dioxin and dibenzofurans, and dioxin-like polychlorinated biphenyls in the waters from River Kanzaki, running through Osaka urban area Japan. J Environ Sci 25:441-451

Kumar B, Kumar SSS, Sharma C (2012) Distribution of polychlorinated biphenyls in surface waters of various sources from national capital region Delhi India. J Nat Sci Res 2:26-37

Lee RG, Coleman P, Jones JL, Jones KC, Lohmann R (2005) Emission factors and importance of PCDD/Fs, PCBs, PCNs, PAHs and PM10 from the domestic burning of coal and wood in the UK. Environ Sci Technol 39:1436-1447

Müller B, Berg M, Yao ZP, Zhang XF, Wang D, Pfluger A (2008) How polluted is the Yangtze river? Water quality downstream from the Three Gorges Dam. Sci Total Environ 402:232-247

Van den Berg M, Birnbaum LS, Denison M, De Vito M, Farland W, Feeley M et al (2006) The 2005 World Health Organization reevaluation of human and mammalian toxic equivalency factors for dioxins and dioxin-like compounds. Toxicol Sci 93:223-241

Zhang J (1995) Geochemistry of trace metals from Chinese River/ Estuary systems: an overview. Estuar Coast Shelf Sci 41:631-658

Zheng MH, Bao ZC, Zhang B, Xu XB (2001) Polychlorinated dibenzo-p-dioxins and dibenzofurans in paper making from a pulp mill in China. Chemosphere 44:1335-1337 